\title{
Experiments Duplicate Mysterious Rock Patterns
}

\author{
Rainwater runoff can erode the surface of a water-soluble rock, scarring it \\ with hundreds of parallel channels.
}

By Katherine Wright

$\prod$ he limestone cliffs of mountain ranges across Europe, including the French Alps and the Slovenian Karen, are scarred with deep channels thought to have been etched by rainwater. These rock formations have not been fully explained, but a team of researchers has now shown that under controlled conditions, water flowing over dissolvable rock-like materials can etch grooves that strongly resemble those found in nature [1]. The experiment could serve as a test-bed for developing theories of water-produced erosion patterns in rocks.

From the ripples seen in sand dunes to the hexagonal columns found in volcanic remains (see Synopsis: Cracking Up), physicists have long been fascinated by the formation mechanisms of geological patterns. One pattern type, called rillenkarren, consists of parallel grooves a few centimeters wide and a few tens of centimeters long. This pattern is typically
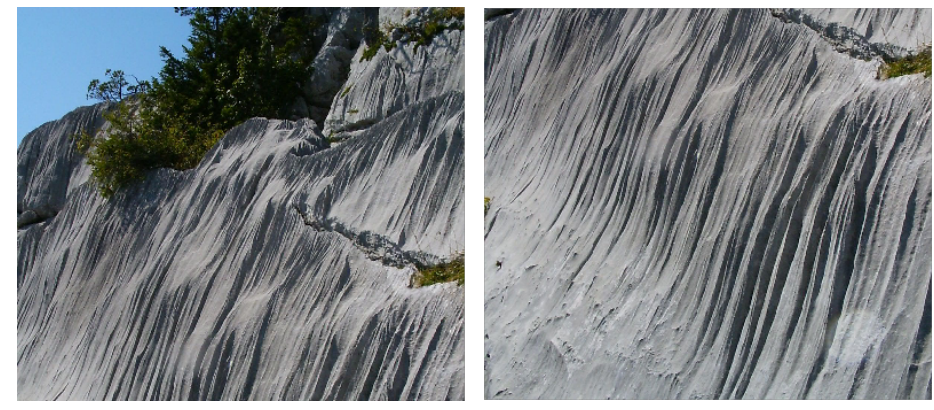

Sharp alignment. Natural rillenkarren appear as long, parallel grooves, as seen in these patterns found in limestone rocks in the French Alps.

Credit: Ymaup/Wikimedia Commons

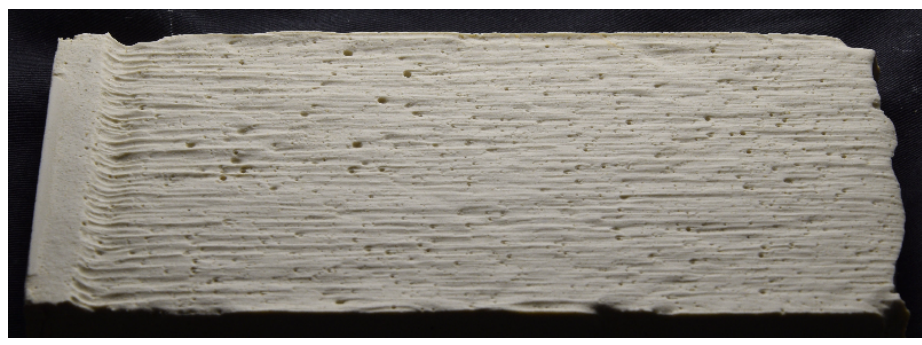

Groovy rocks. Lab experiments that flow water over a slab of plaster successfully replicate erosion patterns found on rocks. Credit: A. Guérin et al. [1]

found on the surfaces of water-soluble rocks, such as limestone or gypsum. Geoscientists believe that rainwater produces rillenkarren by chemically dissolving the rock, rather than by scouring it. However, researchers don't know why the dissolving process produces grooves instead of a smooth surface.

In 1980, the idea that water flowing over rocks could generate groove-like patterns received support from an experimental study [2]. The experiments used a rain simulator that directed drops of water to the surface of a solid. The subsequent etching of grooves led the team to suggest that impacting raindrops were needed to start the formation of the grooves. But the researchers didn't demonstrate experimentally that raindrop impacts are necessary, and they didn't vary the flow rate or observe the evolution of the groove structure.

As a starting point for future studies of the phenomenon, Michael Berhanu of the University of Paris and colleagues built a raindrop-free experiment with more controls and with the ability to track the etched structures over time. They flowed a thin, homogenous film of water over two rock substitutes that 
dissolve more rapidly than real rocks. One was a paving-stone-sized block of plaster, and the other was a similarly sized slab of Himalayan pink salt. Plaster is largely made of gypsum, while the salt was a proxy for limestone. The team tilted each block to allow water to flow down its face and tracked its surface topography using a laser profiler.

In the plaster, narrow, millimeter-wide grooves developed after a few tens of minutes. The grooves began at the top edge and slowly extended in width, length, and depth, until, after a few hours, they spanned the full length of the block. At this point, the grooves were deep enough that the crests between them emerged from the water film. The team observed the same groove evolution in the salt slabs but on much faster timescales: the grooves appeared within a minute of water flow and spanned the whole block in under 5 minutes.

Comparing the final groove patterns to those of naturally occurring rillenkarren, the team found a strong resemblance, although Berhanu notes that the lab-produced grooves were narrower. This difference likely results from the short duration of the experiments -55 hours for the plaster and a few tens of minutes for the salt. Berhanu is convinced that the team will obtain wider grooves with longer-duration experiments.

"Our experiments show that a layer of water flowing over a rock is sufficient to create grooves and that impacting drops are not necessary," Berhanu says. "The finding could change how researchers think about these patterns" and about other patterns based on dissolution.

These results present a "major step forward," providing the first experimental insights into the initial, most important step of pattern formation, says Øyvind Hammer, a geologist at the University of Oslo. "These [insights] are invaluable for informing and validating theories and numerical modeling."

Katherine Wright is a Senior Editor for Physics.

\section{REFERENCES}

1. A. Guérin et al., "Streamwise dissolution patterns created by a flowing water film," Phys. Rev. Lett. 125, 194502 (2020).

2. J. R. Glew, and D. C. Ford, "A simulation study of the development of rillenkarren," Earth Surf. Process. Landf. 5, 25 (1980). 